
Not for reproduction, distribution or commercial use.

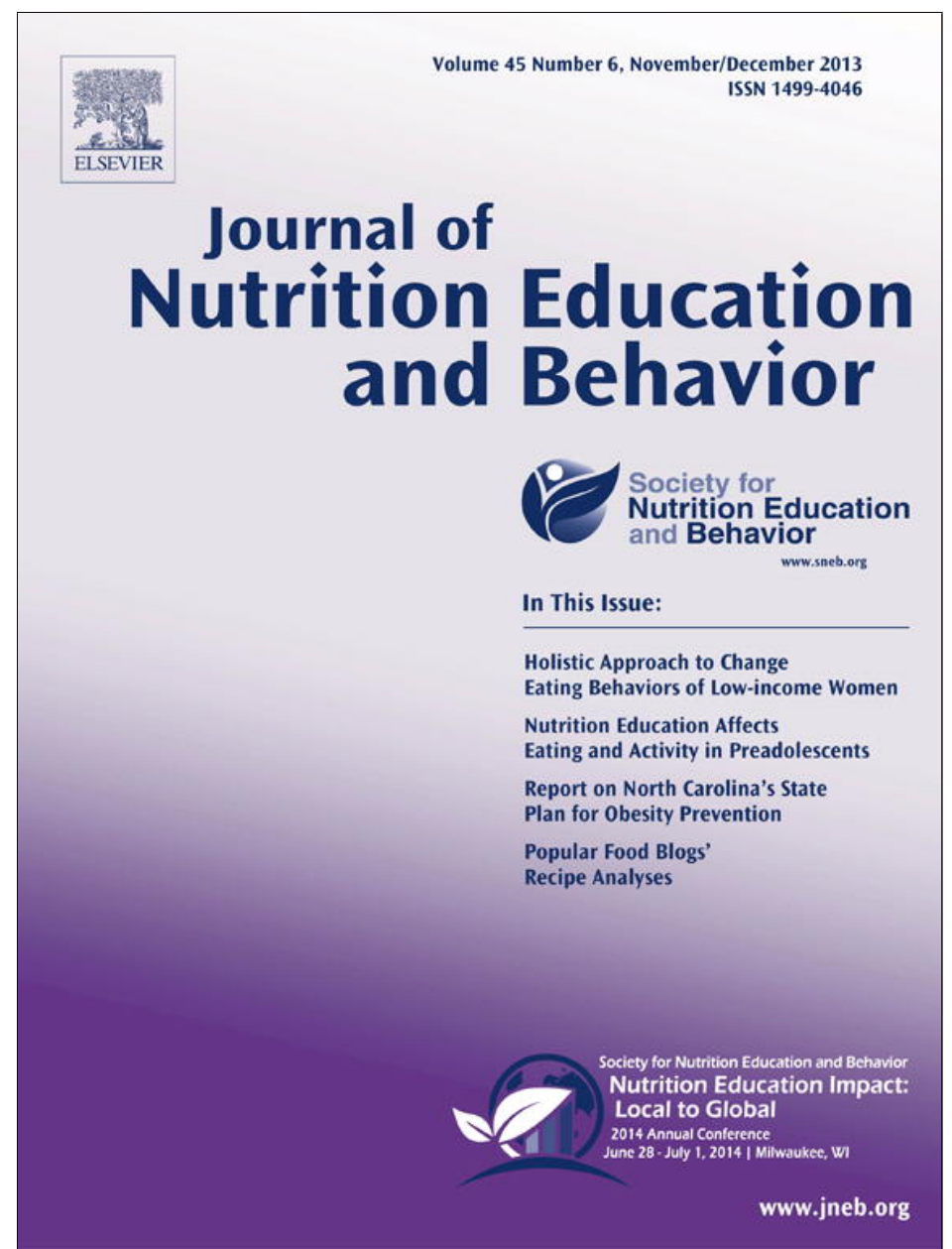

This article appeared in a journal published by Elsevier. The attached copy is furnished to the author for internal non-commercial research and education use, including for instruction at the authors institution and sharing with colleagues.

Other uses, including reproduction and distribution, or selling or licensing copies, or posting to personal, institutional or third party websites are prohibited.

In most cases authors are permitted to post their version of the article (e.g. in Word or Tex form) to their personal website or institutional repository. Authors requiring further information regarding Elsevier's archiving and manuscript policies are encouraged to visit: 


\title{
Efficacy and Consumer Preferences for Different Approaches to Calorie Labeling on Menus
}

\author{
Jocelyn Pang, BSc; David Hammond, PhD
}

\begin{abstract}
Objective: To evaluate the efficacy and consumer preferences of calorie labeling on menus.

Design: Between-group experiment. Participants were randomized to view menu items according to 1 of 4 experimental conditions: no calorie information, calorie-only information, calorie plus health statement (HS), and calorie plus the Physical Activity Scale. Participants selected a snack and then rated menus from all conditions on the level of understanding and perceived effectiveness.

Setting: University of Waterloo, Canada.

Participants: A total of 213 undergraduate university students recruited from classrooms.

Main Outcome Measures: The calorie amount of menu selection and ratings of understandability and perceived effectiveness.

Analysis: Linear regression models and chi-square tests.

Results: Participants who selected items from menus without calorie information selected snacks with higher calorie amounts than participants in the calorie-only condition $(P=.002)$ and the calorie plus HS condition $(P=.001)$. The calorie plus HS menu was perceived as most understandable and the calorie plus calorie plus Physical Activity Scale menu was perceived as most effective in helping to promote healthy eating.

Conclusions and Implications: Calorie labeling on menus may assist consumers in making healthier choices, with consumer preference for menus that include contextual health statements.

Key Words: nutrition labeling, menu planning, consumer health information, health policy ( $J$ Nutr Educ Behav. 2013;45:669-675.)
\end{abstract}

\section{INTRODUCTION}

Obesity has been identified as one of the leading challenges to public health. ${ }^{1}$ Obesity has been associated with a wide range of chronic diseases, including coronary heart disease, stroke, high blood pressure, and type 2 diabetes. ${ }^{2,3}$ In Canada, the prevalence of overweight and obese Canadian adults in 2008 was 62\%, with obesity rates approximately doubling in all age groups over the previous 25 years. Obesity has increased among all age groups and socioeconomic strata, and in all geographic regions; however, socioeconomic disparities are apparent, with significantly higher levels of obesity among aboriginal populations in particular. ${ }^{4}$

Changing dietary patterns and increased energy consumption are primary factors in the rise in obesity, along with reduced energy expenditure from declining levels of physical activity. ${ }^{3}$ Food consumed outside the home accounts for an increasing proportion of the North American diet and has contributed to overall levels of increased energy consumption. $^{5}$ Estimates suggest that the average Canadian household visits a restaurant for a meal or snack approximately 520 times per year, spending $30 \%$ of their food budget on food services. ${ }^{6}$ Food eaten outside the home is associated with higher

School of Public Health and Health Systems, University of Waterloo, Waterloo, Canada Address for correspondence: David Hammond, PhD, School of Public Health and Health Systems, University of Waterloo, 200 University Ave West, Waterloo, Ontario N2L 3G1, Canada; Phone: (519) 888-4567 (ext 36462); Fax: (519) 886-6424; E-mail: dhammond@uwaterloo.ca

(C)2013 SOCIETY FOR NUTRITION EDUCATION AND BEHAVIOR

http://dx.doi.org/10.1016/j.jneb.2013.06.005

Journal of Nutrition Education and Behavior • Volume 45, Number 6, 2013

calorie and fat intake, as well as lower intake of fiber, calcium, fruit, and vegetables, ${ }^{4,7-11}$ and excess weight gain in prospective studies. ${ }^{12-15}$ Furthermore, restaurant patrons have little understanding of the nutrition content of food consumed outside the home. For example, Burton et $\mathrm{al}^{16}$ reported that consumers significantly underestimate the caloric content of menu items, with actual calorie counts approximately double the estimated number of calories.

Regulations requiring nutrition information on menus and menu boards represent a population-level intervention to promote healthier eating outside the home. ${ }^{5}$ In 2008, New York City was the first jurisdiction in North America to require that calorie amounts be posted on menus and menu boards of restaurant chains. ${ }^{17}$ Focus groups with New York City residents found support for the regulation but some skepticism toward its effectiveness. ${ }^{18}$ In March, 2010, the United States Food and Drug Administration (FDA) proposed a federal regulation that will require calorie 
labeling on all menus and menu boards in restaurant chains with $\geq 20$ outlets, in addition to a succinct health statement regarding calorie intake: "a 2,000 calorie diet is used as the basis for general nutrition advice; however, individual calorie needs may vary." ${ }^{19}$ The rationale for the health statement is to provide consumers with a context for the calorie numbers displayed on menus. ${ }^{20}$ Implementation of these regulations must occur within 6 months of the final rule, which is anticipated by the end of 2013. ${ }^{19}$ Currently, there are no requirements in Canada to post calorie labels in restaurants.

Consumers have indicated strong support for nutrition information, and many claim that they would select foods and beverages with lower calories if calorie information were available. ${ }^{21,22}$ Evidence regarding the efficacy of menu labeling is mixed. Some studies report no change $\mathrm{e}^{23-26}$ or increased calorie intake of ordered items ${ }^{27}$ associated with calorie labeling on menus, whereas other studies indicate a significant decrease in calorie levels. ${ }^{28-33}$

Calorie labeling on menus can take several forms. Regulations in many jurisdictions require only the calorie numbers; alternatively, a descriptive statement can accompany numeric information, such as the health statement from the FDA proposed regulation. Roberto et $\mathrm{al}^{34}$ compared consumer preferences of calorie-only labels and calorie labels with recommended daily calorie intake and found that consumers exposed to both conditions ordered items with fewer calories and had an improved ability to estimate calories consumed compared with when no calorie information was given. However, consumers exposed to calorie labels with the recommended daily caloric intake were found to have a lower average calorie intake when what they ate after the study was taken into account. Similarly, a front-of-package study conducted by van Kleef et $\mathrm{al}^{35}$ found that consumers preferred the inclusion of a health statement with caloric information because it provided them with a reminder of the daily recommended caloric intake. In addition, a consumer preference study found that about $60 \%$ of participants found the inclusion of daily calorie needs to be useful or very useful. ${ }^{36}$

Another novel method of displaying calories is to include a physical activity scale (PAS) with calorie information. Presenting calories with a PAS was shown to be more effective in reducing calories in beverage purchases by adolescents at risk for obesity than calorie-only labels and calorie labels with a health statement. ${ }^{37}$ The use of a PAS was preferred by those who thought it would motivate them to exercise more, as well as by those who lead an active lifestyle and therefore found it relevant. $^{36}$ A front-of-package calorie labeling study also showed that consumers felt motivated by the PAS, although most consumers who preferred this menu format were younger adults. In contrast, some thought that the PAS focused too much on health, which caused guilt and took pleasure away from eating. ${ }^{35}$

To date, there is limited literature that assesses and compares different point-of-purchase menu formats. The current study sought to evaluate the effectiveness and consumer preferences of different formats for displaying calorie information on menus through assessing participant snack selection in a hypothetical purchase scenario. More specifically, the study examined the efficacy of 4 calorie menu formats: (1) a menu with no calorie information, (2) a menu with calorie information only, (3) a menu with calorie information and the recommended daily amounts required in the FDA regulation, and (4) a menu with calorie information and a PAS.

\section{METHODS}

\section{Study Design}

The study was conducted as a between-group experiment in which participants were randomized to 1 of 4 experimental conditions based on calorie menu formats. The main outcome measures were the calorie amount of menu selection and ratings of understandability and perceived effectiveness.

Participants and recruitment. Participants were undergraduate students over 18 years of age, who were en- rolled at the University of Waterloo, Ontario, Canada. Participants were recruited from 4 undergraduate classes in Kinesiology and Health Studies, in which course instructors gave permission for recruitment. All 4 classes were health-related classes, although participant majors were not documented.

There were 371 eligible participants, based on the sum of the total enrolment of the courses. All students who attended the class on the date of the study were provided with an anonymous study questionnaire as they entered the classroom. Student within each class were randomly assigned to 1 of 4 experimental conditions (described below) and provided with the corresponding study materials. Students were provided with a brief overview of the study and were invited to participate in the study. Participants returned their surveys immediately after completion. Students who chose not to participate were also asked to submit their blank surveys in the envelope. The survey was approximately $5 \mathrm{~min}$ utes long.

Research ethics. The study received ethic clearance from the Office of Research Ethics, Human Research Ethics Committee, at the University of Waterloo. Consent forms were not required because the survey was anonymous and posed minimal risk to participants. Instead, implied consent was achieved through participants returning the anonymous survey.

Experimental conditions. Figure 1 shows the menu format conditions used in this study. (1) The no-calorie menu did not provide any calorie information and was included as a control condition. (2) The calorieonly menu provided calorie information next to each food item and is similar to current practice in New York City and other jurisdictions in which menu labeling has been mandated. (3) The health statement (HS) menu included calorie information, as well as the following statement, based on proposed wording in the FDA regulations: "The recommended daily energy intake for adults is 2,000 calories." (4) The PAS menu 


\begin{tabular}{|c|c|c|c|}
\hline \multicolumn{4}{|l|}{ No-Calories Condition } \\
\hline \multicolumn{2}{|l|}{ Chocolate Chip Muffin } & \multicolumn{2}{|l|}{ Apple Fritter Donut } \\
\hline \multicolumn{2}{|l|}{ Low Fat Double Berry Muffin } & \multicolumn{2}{|l|}{ Chocolate Dip Donut } \\
\hline \multicolumn{2}{|l|}{ Blueberry Muffin } & \multicolumn{2}{|c|}{ Sour Cream Glazed Donut } \\
\hline \multicolumn{4}{|c|}{ Calories-Only Condition } \\
\hline Chocolate Chip Muffin & $410 \mathrm{cal}$ & Apple Fritter Donut & $300 \mathrm{cal}$ \\
\hline $\begin{array}{l}\text { Low Fat Double Berry } \\
\text { Muffin }\end{array}$ & $290 \mathrm{cal}$ & Chocolate Dip Donut & $210 \mathrm{cal}$ \\
\hline Blueberry Muffin & $340 \mathrm{cal}$ & $\begin{array}{l}\text { Sour Cream Glazed } \\
\text { Donut }\end{array}$ & $340 \mathrm{cal}$ \\
\hline \multicolumn{4}{|c|}{ Health Statement Condition } \\
\hline Chocolate Chip Muffin & $410 \mathrm{cal}$ & Apple Fritter Donut & $300 \mathrm{cal}$ \\
\hline $\begin{array}{l}\text { Low Fat Double Berry } \\
\text { Muffin }\end{array}$ & $290 \mathrm{cal}$ & Chocolate Dip Donut & $210 \mathrm{cal}$ \\
\hline Blueberry Muffin & $340 \mathrm{cal}$ & & ded c \\
\hline Sour Cream Glazed Donut & $340 \mathrm{cal}$ & & \\
\hline \multicolumn{4}{|c|}{ Physical Activity Scale Condition } \\
\hline Chocolate Chip Muffin & $\begin{array}{l}410 \mathrm{cal} \\
\text { (40 min of running) }\end{array}$ & Apple Fritter Donut & $\begin{array}{l}300 \mathrm{cal} \\
\text { (30 min of running) }\end{array}$ \\
\hline $\begin{array}{l}\text { Low Fat Double Berry } \\
\text { Muffin }\end{array}$ & $\begin{array}{l}290 \mathrm{cal} \\
(30 \mathrm{~min} \text { of running) }\end{array}$ & Chocolate Dip Donut & $\begin{array}{l}210 \mathrm{cal} \\
(20 \mathrm{~min} \text { of running) }\end{array}$ \\
\hline Blueberry Muffin & $340 \mathrm{cal}$ & & \\
\hline Sour Cream Glazed Donut & $\begin{array}{l}\text { (35 min of running) } \\
340 \mathrm{cal} \\
(35 \mathrm{~min} \text { of running) }\end{array}$ & 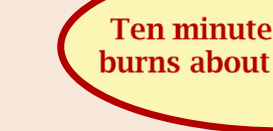 & 0 \\
\hline
\end{tabular}

Figure 1. Menus for snack items, by experimental conditions, in a menu labeling study to assess efficacy and consumer preference.

included calorie information and the statement "Ten minutes of running burns about 100 calories." The approximate time required to burn off the calories was also included in brackets for each food item. Menu items were selected from Tim Horton's, the leading restaurant chain in Canada. Calorie amounts for each item were drawn from nutritional information provided on the company's publicly accessible Web site as of November, 2012.

\section{Measures}

Sociodemographic variables and moderators. The study questionnaire assessed demographic information, including age, gender, and perceived importance of a healthy diet. Perceived importance of healthy diet was measured with the question "How important is a healthy diet to you," and was measured on a 5-point Likert scale $(1=$ not at all important; $2=$ a little important; $3=$ somewhat important; 4 = very important; and 5 = extremely important). These measures were collected to ensure that participants were similar in confounding variables among experimental conditions.

Menu format measures. Participants were randomized to 1 of the 4 menu formats and asked to select a snack item from the menu printed in their survey booklet. Purchase intention was assessed through participants' indication of which menu item they would order: "If you were to order a snack from the menu below, which item would you choose?" This was the main outcome of interest and was analyzed to determine the effectiveness of the calorie labels in reducing caloric value of the hypothetical snack selections.

Consumer preference of menu format. After selecting their menu item, participants were shown all 4 menu formats and asked to report their preferences with respect to ease of understanding ("Which menu shows calorie information in the MOST/LEAST UNDERSTANDABLE way") and effectiveness in promoting healthy eating ("Which menu would be MOST/LEAST EFFECTIVE in helping to promote healthy eating"). Participants indicated their preference by circling a letter corresponding to each menu format. The order in which the menu formats were presented to participants was randomized to control for any order effect. Results from these questions were used to assess consumer preference between calorie labels.

\section{Analysis}

A total of 214 participants completed the survey. One participant did not indicate his age and was excluded from analysis. Chi-square tests were used to compare the sample profile across experimental conditions for gender; ANOVA tests were used to examine age and perceived importance of a healthy diet across conditions. Variable distributions were checked for normality using skewness and kurtosis tests. Linear regression models were used to examine the effect of experimental condition on the calorie level of the snack choice. Models were adjusted for age, gender, and perceived importance of a healthy diet. Cross-tabs were used to examine the association among experimental condition and preference for menu formats. $P<.05$ was used as the cutoff for statistical significance for all analyses (version 15.0, SPSS Inc, Chicago, IL, 2007). 
Table. Sample Characteristics of University of Waterloo, Ontario, Canada Students Participating in Menu Labeling Study to Assess Efficacy and Consumer Preference, $2012(n=213)$

\begin{tabular}{|c|c|c|c|c|c|}
\hline Condition & $\begin{array}{l}\text { No Calories } \\
\qquad(n=61)\end{array}$ & $\begin{array}{l}\text { Calories Only } \\
\quad(n=56)\end{array}$ & $\begin{array}{l}\text { Health Statement } \\
\qquad(\mathrm{n}=46)\end{array}$ & $\begin{array}{l}\text { Physical Activity } \\
\text { Scale }(n=50)\end{array}$ & $\begin{array}{c}\text { Total } \\
(n=213)\end{array}$ \\
\hline Age, y $(\text { mean }[S D])^{a}$ & $20.5(1.0)$ & $20.6(1.3)$ & $20.8(1.1)$ & $20.5(1.1)$ & $20.6(1.1)$ \\
\hline \multicolumn{6}{|l|}{ Gender, n (\%) } \\
\hline Males & $15(25)$ & $27(48)$ & $21(46)$ & $10(20)$ & $73(34)$ \\
\hline Females & $46(75)$ & $29(52)$ & $25(54)$ & $40(80)$ & $140(66)$ \\
\hline \multicolumn{6}{|c|}{ How important is a healthy diet to you? $\mathrm{n}(\%)^{\mathrm{b}}$} \\
\hline Somewhat important or less & $21(34)$ & $18(32)$ & $19(41)$ & $16(32)$ & $74(35)$ \\
\hline Very important & $34(56)$ & $31(55)$ & $20(44)$ & $25(50)$ & $110(52)$ \\
\hline Extremely important & $6(10)$ & $7(1)$ & $7(15)$ & $9(18)$ & $29(13)$ \\
\hline
\end{tabular}

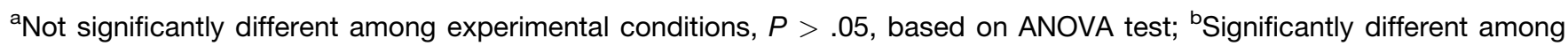
experimental conditions, $P<.05$, based on chi-square test.

\section{RESULTS}

\section{Sample Characteristics}

The Table shows the sample characteristics. There were no statistically significant differences among the 4 conditions for age or reported importance of a healthy diet. There was a significant difference for gender across the conditions $\left(\chi^{2}=14.8\right.$; $P=.002)$, such that the no-calories condition had significantly more females than males compared with the calories-only $(P=.009)$ and HS $(P=.003)$ conditions. The PAS condition also had significantly more females than males compared with the calories-only condition $(P=.003)$ and HS condition $(P=.009)$. Age, gender, and importance of a healthy diet also all had a normal distribution based on the Kolmogorov-Smirnov test $(P=.17$, .42 , and .29 , respectively) and the Shapiro-Wilk test $(P=.93, .60$, and .84 , respectively).

\section{Snack Choices}

Figure 2 shows the mean calorie level for menu selections across conditions. Significant differences were observed across conditions ( $\mathrm{F}=2.4$; $P=.02)$. Participants in the nocalories condition chose snacks with significantly more calories than the calories-only condition $(\beta=34.5$; $P=.002)$ and the HS condition $(\beta=37.5 ; P=.001)$, but not significantly more than the PAS condition $(\beta=21.5 ; P=.05)$. There was no difference in snack calories among the calories-only, HS, and PAS conditions.

\section{Point-of-Purchase Menu Format Preference}

Figure 3 displays participants' responses for the "most" and "least" understandable menu format in showing calorie information, as well as "most" and "least" effective menu format in helping promote healthy eating. Experimental condition was not associated with participant preference for menu formats. The majority of participants selected the no-calories menu format as the least understandable $(88.2 \%)$ and the least effective (91.5\%). Participants most commonly selected the HS menu format as the most understandable (47.2\%), followed closely by the PAS menu format $(42.9 \%)$. Meanwhile, the PAS menu format was most frequently selected as the most effective menu format $(64.0 \%)$, with only about half as many participants selecting the HS menu format for the same category (34.6\%). The distribution of responses for both the "understandable" and "effective" measures was statistically significant $(P<.001$ for all $)$.

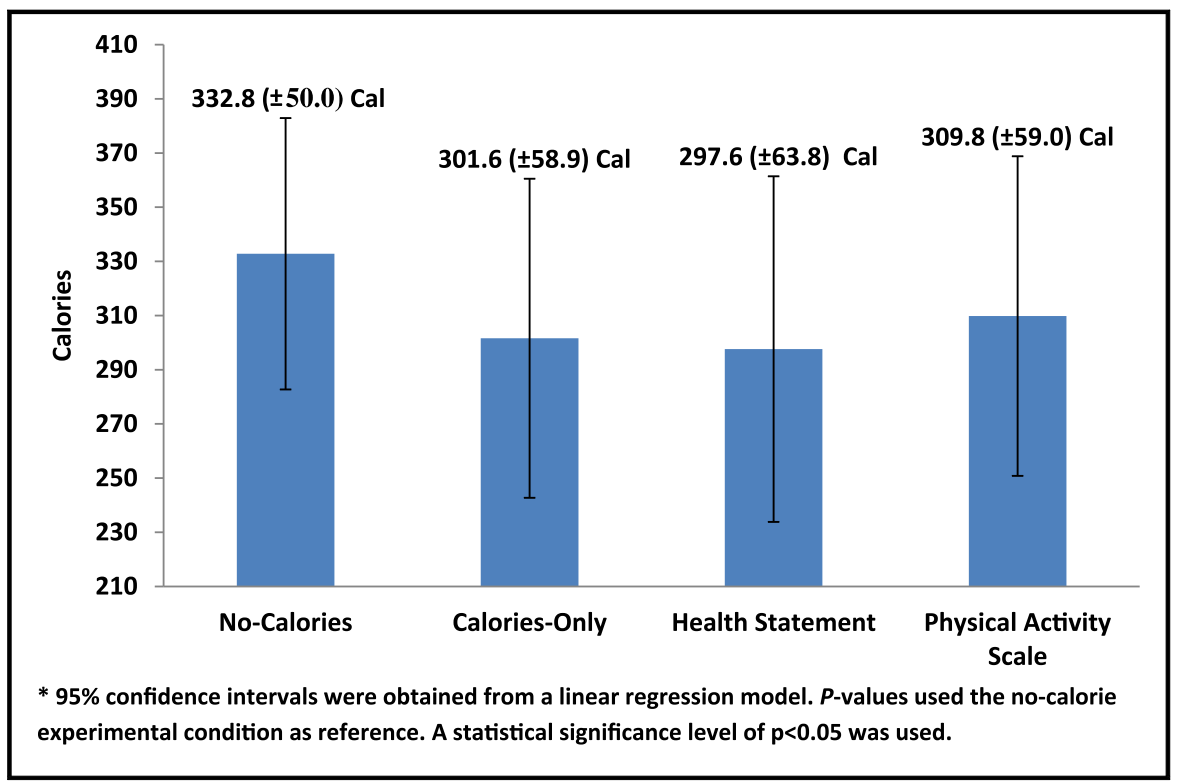

Figure 2. Mean calories in snack items selected by University of Waterloo students from different menus, by experimental conditions, to assess the efficacy of menu $(n=211)$. 


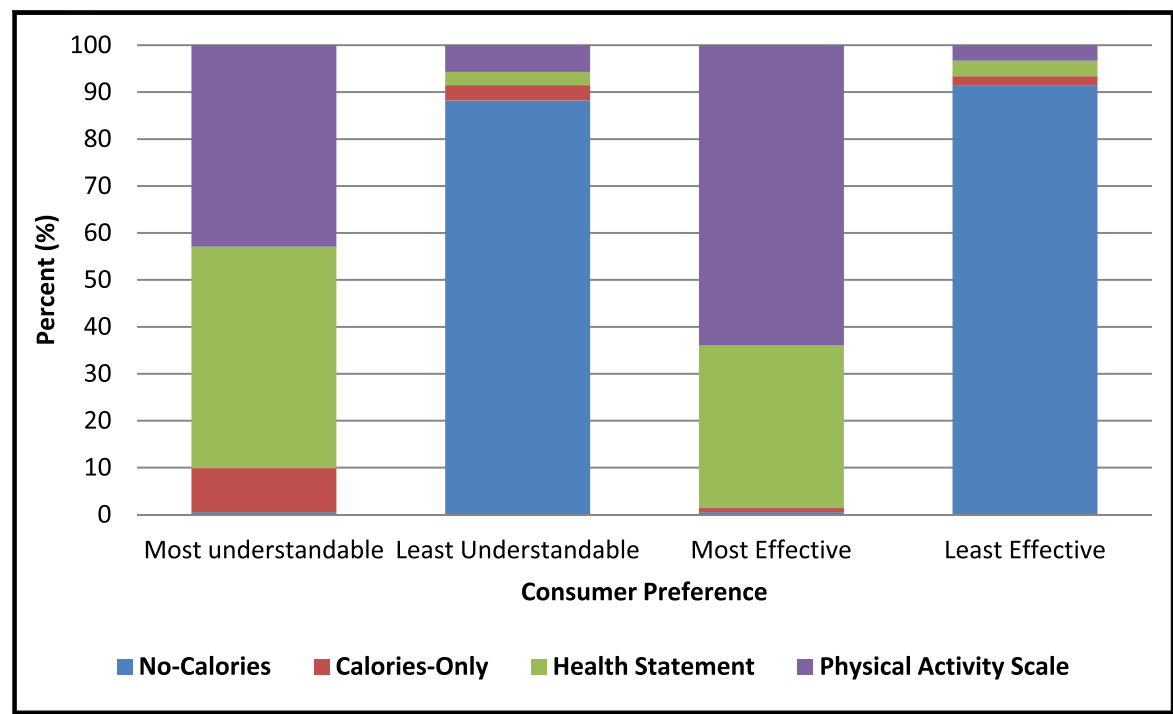

Figure 3. Menu format understanding and effectiveness, as rated by University of Waterloo students to assess consumer preference, by experimental conditions ( $n=212$ ).

\section{DISCUSSION}

This study examined the effect of different calorie labels on calorie intake as well as consumer preference of calorie labels. It compared calorie labels that are already in use in the United States, and proposed calorie labels and a novel format with past success. The findings indicate that menu labeling format was significantly associated with intended snack item selection. Participants who viewed menus with calorie levels and those who viewed menus with calories and a statement of the recommended daily amount selected food items with significantly less calories than did participants who viewed a menu with no calorie information. The difference in calorie level among groups was approximately 9\% for both conditions. There was a trend toward lower calorie selection for participants who viewed menus with calorie amounts and the corresponding amount of physical activity that would be required to burn the calories; however, the difference with the no-calorie menu was not statistically significant.

Of the different menu formats examined in this study, the menu with the recommended daily calorie amount was perceived as most understandable. This is consistent with previous research showing that the daily amounts provide important context for calorie numbers, which are otherwise difficult for consumers to interpret: Although consumers can use calorie amounts to identify which items have higher calorie content, many consumers do not know whether the amounts represent a high or low amount with respect to their recommended intake. ${ }^{20,38}$ Past research has also indicated that exposure to the menus with information on daily recommended amounts may increase consumer awareness of calories throughout the entire day. Roberto et $\mathrm{al}^{34}$ found that when taking into account what participants consumed after their study, participants exposed to calorie labels with the recommended daily caloric intake had a lower average calorie intake than those exposed to calorieonly labels. These findings provide support for the inclusion of daily recommended statements in the proposed FDA regulation as a supplement to calorie numbers. However, the health statement currently used on food packages and proposed by FDA regulation uses 2,000 calories per day as a guideline for the general population, whereas individual calorie needs may vary from this guideline.

The menu with the PAS was perceived to be the most effective in promoting healthy eating. This preference may reflect the sample of young adults recruited for the study. Past research has found that menus with a PAS format are most likely to be preferred by younger consumers and by those who feel that the menu format motivates them to exercise; in contrast, individuals who were unable to exercise, such as the frail elderly or people with disabilities, found the scale to be discouraging and irrelevant. ${ }^{35,36}$ Therefore, the PAS menu format may not be as positively viewed in the general population. In addition, despite the stated preference for this format, the calorie levels of the snack selections among participants assigned to view the PAS menu were not significantly different from the control condition. However, there was a trend toward statistical significance, and another study found the PAS calorie label to lower calorie intake effectively. ${ }^{37}$ Also, the energy expenditure statement used on this PAS menu is meant as a guideline for the population, but actual calories burned through running may vary among individuals.

This study contained several strengths and limitations. First, the study looked at calorie labels and the impact it would have on lowering calories in the selection of 1 snack item, but not how it would influence a healthy diet in terms of nutrition or calorie intake throughout the entire day. Calories are only 1 factor in a healthy diet-indeed, none of the snack items included in the current study are likely to be promoted as healthy options. Nevertheless, the current study sought to examine calorie labeling given the direct implications for obesity. Participants were a homogeneous population of university students enrolled in health-related course. Age and education level are known to be important factors in both diet and levels of physical activity. ${ }^{39,40}$ Therefore, the results of this study may apply only to more educated young adults and additional research is required to examine whether the current findings can be generalized to a more representative sample. Another limitation is that the primary outcome measure was based on snack selection intentions, rather than actual behavioral measures of food selection in a more naturalistic setting. For instance, some participants may have reported that they would choose lower caloric items to appear in a positive light within the context of the study. 
Also, because this study was not conducted in a naturalistic setting, factors that may influence food choice were not taken into consideration, such as personal preference for food, the social context, and the environmental context. ${ }^{41}$ Also, this study did not collect information on participant body mass index or assess participants for perceived hunger, both of which could have affected snack selection. Nevertheless, these biases would apply equally across the sample and are unlikely to account for the differences observed among experimental conditions. Another limitation is that although the importance of a healthy diet was assessed, the importance of living a healthy active lifestyle was not. This may have influenced participant preference for the PAS menu format. As such, it is unknown whether the preference for the PAS menu found in this study was limited to this population of students. A strength of this study was the experimental design, including randomization to condition, and the use of both between-subject measures to examine the potential impact of different menu formats and withinsubject measures to examine participant preference among the 4 menu formats.

\section{IMPLICATIONS FOR RESEARCH AND PRACTICE}

This study provides preliminary evidence that menu labeling may promote healthier food selection among young adults. The findings also suggest that integrating a statement on recommend daily amounts can increase comprehension of calorie amounts displayed on menus. Overall, the study provides support to the FDA's proposals to require calorie information on menus and a statement on recommend daily amounts, which represent a change from existing regulations in jurisdictions such as New York City.

Future research should examine the efficacy of these statements in more diverse populations and in more naturalistic settings. In particular, studies could examine awareness, use, and the potential effect of these statements after the implementation of the FDA's regulations. These future studies may consider methodology approaches that measure actual purchases and calorie intake instead of purchase intention. The authors recommend that studies also evaluate how individual differences in sociodemographics, health values, and preexisting nutrition knowledge may impact the effectiveness of calorie labels. One population of particular interest may be those who are not health literate, because this population may require graphic representation of the calorie labels and accompanying health statements.

\section{ACKNOWLEDGMENTS}

This work was supported by a grant from the Canadian Cancer Society Research Institute. Additional support was provided by the Propel Centre for Population Health Impact, a Canadian Institutes of Health Research New Investigator Award (to D.H.), and a Canadian Cancer Society Research Institute Junior Investigator Award (to D.H.). The authors thank Christine White for assistance with the study.

\section{REFERENCES}

1. Bassett MT, Perl S. Obesity: the public health challenge of our time. Am J Public Health. 2004;94:1477.

2. Obesity: Halting the Epidemic by Making Health Easier. At a Glance 2011. Atlanta, GA: National Center for Chronic Disease Prevention and Health Promotion; 2011.

3. Ofei F. Obesity - a preventable disease. Ghana Med J. 2005;39:98-101.

4. Obesity in Canada. Ottawa, Ontario: Canada: Public Health Agency of Canada and Canadian Institute for Health Information; 2011 . http://www.phac-aspc.gc.ca/ hp-ps/hl-mvs/oic-oac/assets/pdf/oic-oaceng.pdf. Accessed July 18, 2013.

5. Dumanovsky T, Nonas CA, Huang CY, Silver L, Bassett MT. What people buy from fast-food restaurants: caloric content and menu item selection, New York City 2007. Obesity. 2009;17:1369-1374.

6. Canadians spending more on eating out. Ottawa, Canada: Statistics Canada. http://www41.statcan.ca/2006/0163/ ceb0163_002-eng.htm. Accessed July 10, 2013.
7. Kant AK, Graubard BI. Eating out in America, 1987-2000: trends and nutritional correlates. Prev Med. 2004;38: 243-249.

8. French SA, Story M, Jeffery RW. Environmental influences on eating and physical activity. Annu Rev Public Health. 2001;22:309-335.

9. Satia JA, Galanko JA, Siega-Riz AM. Eating at fast-food restaurants is associated with dietary intake, demographic, psychosocial and behavioral factors among African Americans in North Carolina. Public Health Nutr. 2004;7: 1089-1096.

10. Schmidt M, Affenito SG, StriegelMoore R, et al. Fast-food intake and diet quality in black and white girls: the National Heart, Lung, and Blood Institute Growth and Health Study. Arch Pediatr Adolesc Med. 2005;159: 626-631.

11. Mancino L, Todd J, Lin BH. Separating what we eat from where: measuring the effect of food away from home on diet. Food Policy. 2009; 34:557-562.

12. Pereira MA, Kartashov AI, Ebbeling CB, et al. Fast-food habits, weight gain, and insulin resistance (The CARDIA Study): 15-year prospective analysis. Lancet. 2005;365: 36-42.

13. Thompson OM, Ballew C, Resnicow K, et al. Food purchased away from home as a predictor of change in BMI z-score among girls. Int J Obes (Lond). 2004;28:282-289.

14. Brownell KD. Fast food and obesity in children. Pediatrics. 2004;113:132.

15. Powell LM, Chaloupka FJ, Bao Y. The availability of fast-food and full-service restaurants in the United States: associations with neighborhood characteristics. Am J Prev Med. 2007;33(suppl): S240-S245.

16. Burton S, Creyer EH, Kees J, Huggins K. Attacking the obesity epidemic: the potential health benefits of providing nutrition information in restaurants. Am J Public Health. 2006; 96:1669-1675.

17. Rules of the City of New York, Title 24, New York City Health Code Section 81.50. 2006.

18. Gordon C, Hayes R. Counting calories: resident perspectives on calorie labeling in New York City. J Nutr Educ Behav. 2012;44:454-458.

19. United States Food and Drug Administration. Patient Protection and Affordable Care Act of 2010 on State and 
Local Menu and Vending Machine Labeling Laws Section 4205. 2010.

20. Nestle M. Health care reform in action-calorie labeling goes national. N Engl J Med. 2010;362:2343-2345.

21. Piron J, Smith LV, Simon P, Cummings PL, Kuo T. Knowledge, attitudes and potential response to menu labelling in an urban public health clinic population. Public Health Nutr. 2009;13:550-555.

22. Lando AM, Labiner-Wolfe J. Helping consumers make more healthful food choices: consumer views on modifying food labels and providing point-ofpurchase nutrition information at quick-service restaurants. J Nutr Educ Behav. 2007;39:157-163.

23. Elbel B, Kersh R, Brescoll BL, Dixon LB. Calorie labelling and food choices: a first look at the effects on low-income people in New York City. Health Aff. 2009;28:w1110-w1121.

24. Elbel B, Gyamfi J, Kersh R. Child and adolescent fast-food choice and the influence of calorie labelling: a natural experiment. Int J Obes (Lond). 2011;35:493-500.

25. Finkelstein EA, Strombotne KL, Chan NL, Krieger J. Mandatory menu labelling in one fastfood chain in King County. Washington. Am J Prev Med. 2011;40:122-127.

26. Harnack LJ, French SA, Oakes JM, Story MT, Jeffrey RW, Rydell SA. Effects of calorie labeling and value size pricing on fast food meal choices: results from an experimental trial. Int $J$ Behav Nutr Phys Act. 2008;5:63.

27. Aaron J, Evans R, Mela D. Paradoxical effect of a nutrition labelling scheme in a student cafeteria. Nutr Res. 1995;15: 1251-1261.

28. Bassett MT, Dumanovsky T, Huang C, et al. Purchasing behavior and calorie information at fast-food chains in New York City, 2007. Am J Public Health. 2008;98:1457-1459.

29. Pulos E, Leng K. Evaluation of a voluntary menu-labelling program in full-service restaurants. Am J Public Health. 2010;100:1035-1039.

30. Vadiveloo MK, Dixon LB, Elbel B. Consumer purchasing patterns in response to calorie labeling legislation in New York City. Int J Behav Nutr Phys Act. 2011;8:51-60.

31. Chu YH, Frongillo EA, Jones SJ, Kaye GL. Improving patrons' meal selections through the use of point-ofselection nutrition labels. Am J Public Health. 2009;99:2001-2005.

32. Bollinger B, Leslie P, Sorensen A. Calorie posting in chain restaurants. NBER Working Paper No. 15648. January, 2010. http://www.gsb.stanford. edu/sites/default/files/StarbucksCalorie PostingStudy.pdf. Accessed May 7, 2013.

33. Dumanovsky T, Huang CY, Nonas CA, Matte TD, Bassett MT, Silver LD. Changes in energy content of lunchtime purchases from fast food restaurants after introduction of calorie labelling: cross sectional customer surveys. BMJ. 2011; 343. d4464.

34. Roberto CA, Larsen PD, Agnew H Balk J, Brownell KD. Evaluating the impact of menu labeling on food choices and intake. Am J Public Health. 2010;100:312-318.
35. van Kleef E, van Trijp H, Paeps F, Fernandez-Celemin L. Consumer preferences for front-of-pack calories labeling. Public Health Nutr. 2007;11: 203-213.

36. Fitch RC, Harnack LJ, NeumarkSztainer DR, et al. Providing calorie information on fast-food restaurant menu boards: consumer views. $A m J$ Health Promot. 2009;24:129-132.

37. Bleich SN, Herring BJ, Flagg DD, Gary-Webb TL. Reduction in purchases of sugar sweetened beverages among low-income black adolescents after exposure to caloric information. Am J Public Health. 2012;102:329-335.

38. The Strategic Counsel. Canadians' understanding and use of the nutrition facts table: baseline national survey results. Ottawa, Ontario, Canada: Health Canada; 2011.

39. Health Canada. Do Canadian adults meet their nutrient requirements through food intake alone? Ottawa, Ontario, Canada: Health Canada; 2012. http://hc-sc.gc.ca/fn-an/alt_formats/pdf/ surveill/nutrition/commun/art-nutradult-eng.pdf. Accessed July 18, 2013.

40. Colley RC, Garriguet D, Janssen I, Craig CL, Clarke J, Tremblay MS. Physical activity of Canadian adults: accelerometer results from the 2007 to 2009 Canadian Health Measures Survey. Health Reports. 2011;22:7-14.

41. Eertmans A, Baeyens F, Van den Bergh O. Food likes and their relative importance in human eating behaviour: review and preliminary suggestions for health promotion. Health Educ Res. 2001;16:443-456. 